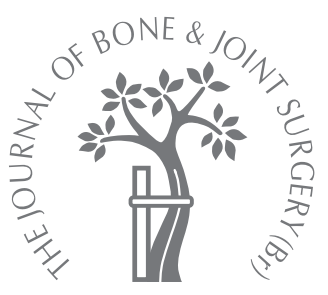

T. M. Lawrence,

R. Wenn,

C. T. Boulton,

C. G. Moran

From the University

Hospital,

Nottingham,

England

\title{
Age-specific incidence of first and second fractures of the hip
}

We determined the age-specific incidence of a second fracture of the hip and compared it with that of a primary fracture in a study population drawn from 6331 patients admitted to Nottingham University Hospital with a primary fracture of the hip over a period of 8.5 years. The incidence of a second fracture was determined using survival analysis. The mean agespecific incidence rates of primary hip fracture were calculated using census data.

The overall incidence of a second fracture was $2.7 \%$ at one year and $7.8 \%$ at 8.5 years. That of a primary fracture was 50 per 100000 in women aged 55 to 64 years rising to 3760 in those aged 84 years and over. The incidence of a second fracture in women aged 55 to 64 years was 2344 per 100000 . Patients of this age had a relative risk of 45 (95\% confidence interval 13 to 155) for further fracture when compared with the population at risk of a first fracture. The incidence of a second fracture in women aged $>84$ years was 2451 per 100000 (relative risk $0.7,95 \%$ confidence interval 0.5 to 0.9 ). A similar trend was seen in men.

Patients sustaining a primary fracture of the hip between the ages of 55 and 64 years have a much greater risk of further fracture than the normal population, whereas those over 84 years have a similar risk. These findings have important implications for the provision of fracture prevention services in primary and secondary care.

A fracture of the hip is often the initial presentation of osteoporosis with affected patients at risk of subsequent osteoporotic fractures at sites such as the wrist, vertebra and the contralateral hip. ${ }^{1-3}$ Numerous studies have investigated the incidence and lifetime risk of primary fracture of the hip. ${ }^{4-7}$ Several others have addressed the incidence of a second fracture. Many have been retrospective in nature ${ }^{8-13}$ and have failed to take account of the mortality after a fracture of the hip. There are a few prospective studies ${ }^{14-18}$ concerning the incidence of a second fracture, but these have not identified the base population in which such fractures occur. To date no study has been able to calculate the age-specific relative risk for a first and second fracture of the hip within the general population.

Identification of those at higher risk of secondary fracture may allow more strategic provision for prevention to be implemented. Our aim was to determine the age-specific incidence of a second fracture and to compare it with the incidence of a primary fracture within the general population.

\section{Patients and Methods}

A prospective study of all patients admitted to the Nottingham University Hospital, with a fracture of the hip was undertaken over a period of 8.5 years between May 1999 and November 2007. Data were collected by independent research assistants (CTB, RW) and included the clinical details and the type of fracture sustained. Accurate mortality data were obtained from the Office for National Statistics. ${ }^{19}$

Nottingham has a single Accident and Emergency Department and all patients from the two local primary care trusts serving the Nottingham area were included in the analysis of population data. Patients who were treated at Nottingham University Hospital but lived outside the catchment area of the Trust (as defined by postal address) were excluded from the analysis to ensure as far as possible that the study population and census data were comparable.

A total of 6331 patients were admitted during the period of study. Of these, 171 aged under 50 years were excluded since most fractures in this group were a result of high-energy trauma. A further 93 with periprosthetic fractures, four with failure of an implant and 13 with bilateral simultaneous fractures were also excluded, as were 617 whose general practitioner's practice was outside the area of the Nottingham primary care trusts. In addition, 
Table I. Details of control and second hip fracture groups

\begin{tabular}{|c|c|c|}
\hline & Second hip fracture & Control \\
\hline Number of patients & 280 & 4746 \\
\hline $\begin{array}{l}\text { Mean age at first hip fracture in years (range } \\
\text { Gender }(\%)\end{array}$ & 81 (55 to 100$)$ & 81 (50 to 107) \\
\hline Men & $45(16)$ & $1154(24)$ \\
\hline Women & $235(84)$ & $3592(76)$ \\
\hline
\end{tabular}

127 were excluded because they had a previous contralateral fracture of the hip prior to April 1999. The remaining 5306 patients formed the study group, with 280 from this group sustaining a second hip fracture within the period of study. The remaining 4746 patients had sustained only one fracture during this period.

Statistical analysis. Kaplan-Meier ${ }^{20}$ curves with the $95 \%$ confidence intervals $(\mathrm{CI})$, were used to determine the incidence of a second fracture of the hip for all 5306 patients. Patients were censored at the end of the follow-up period or death. Microsoft Excel (Microsoft, Redmond, Washington) and SPSS version 14.0 (SPSS Inc., Chicago, Illinois) were used for the analysis with guidance from a statistician (SA). Calculation of age-specific incidence rates of a first and second hip fracture. Population data for Nottingham from the census in year $2001^{21}$ was used for the analysis and matched to the districts covered by the two primary care trusts in Nottingham. Details from the 2001 census $^{21}$ suggested that the elderly population in Nottingham did not change because of migration. The incidence of a first fracture of the hip was calculated from a single-year period (May 1999 to May 2000) and the incidence per 100000 people per year by gender and age group. These were used as the control group.

Patients who were admitted in the following 7.5 years (May 2000 to November 2007) with a primary fracture formed a second series to ensure independence of data. These patients were followed for one year and the incidence of a second fracture within one year of the first was calculated per 100000 people, stratified by age and gender. This allowed the formulation of an age-specific relative risk between the first and second fractures.

\section{Results}

The mean age of the patients was 81 years (50 to 107) and $4062(77 \%)$ (235 sustained two fractures) were women (Table I). The mortality after fracture was $542(10 \%)$ at 30 days, $1063(20 \%)$ at 90 days and $1649(31 \%)$ at one year.

The mean age of the 280 patients who sustained a second fracture of the hip within the study period was 81 years ( 55 to 100$)$ at the time of the first fracture and $235(84 \%)$ were women. The mean interval between fractures was 603 days (3 to 2773). A similar pattern of fracture occurred in both hips in $200(71 \%)$ of these patients. Both fractures were intracapsular in $116(41 \%)$ and extracapsular in $84(30 \%)$.

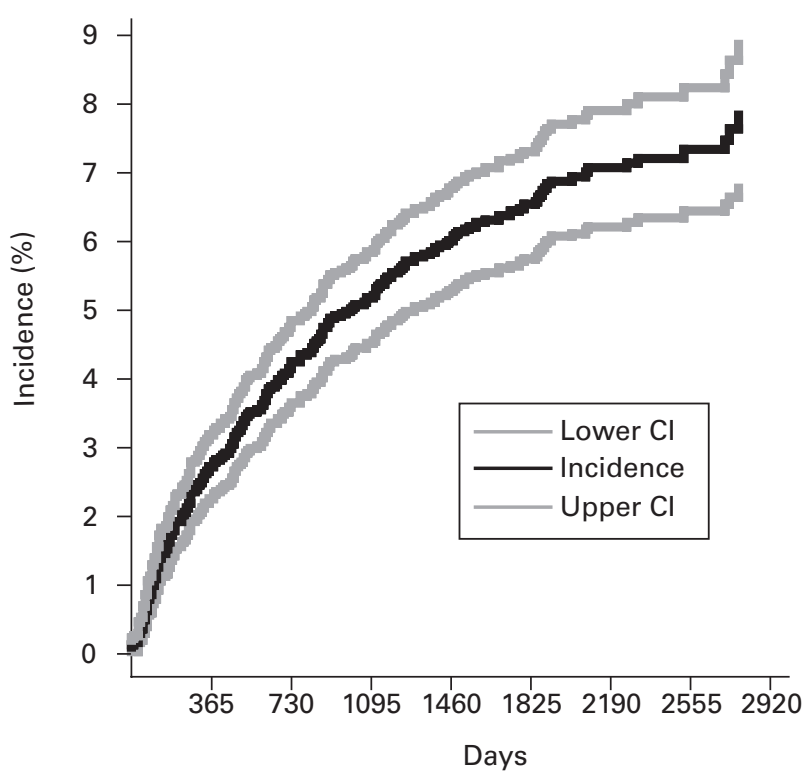

Fig. 1

Graph showing the incidence of a second fracture of the hip in surviving patients with $95 \%$ confidence intervals $(\mathrm{Cl})$.

The mortality after the second fracture was $30(11 \%)$ at 30 days and $95(34 \%)$ at one year.

Survival analysis (Fig. 1) showed that the incidence of a second hip fracture was $0.9 \%(95 \%$ CI 0.6 to 1.2$)$ at 90 days, $2.7 \%$ at one year $(95 \%$ CI 2.3 to 3.2$)$ and $7.8 \%$ at 8.5 years $(95 \%$ CI 6.8 to 8.9$)$. The overall annual incidence was $0.9 \%$ per year in surviving patients. A second fracture appeared to be more common in the first 12 months after the first and $131(47 \%)$ second fractures occurred within this period. The age- and gender-specific incidence of primary fracture of the hip in the population of Nottingham is shown in Table II. The incidence of first fracture increases with age from 50 to 3760 per 100000 population in women between the ages of 55 and 85 years, which equates to a 75 -fold increase. In men, the incidence of primary hip fracture increased 43-fold between the same age groups. The calculated age- and gender-specific rates of incidence of a second hip fracture are shown in Table III, together with the risk ratio of a second versus a first fracture. Unlike that of the first fracture, the incidence of a second fracture did not increase with age. Female patients over the age of 85 had the same or slightly lower risk $(0.7,95 \%$ CI 0.5 to 0.9$)$ 
Table II. Numbers per year and age- and gender-specific rates of incidence per 100000 population of fractures of the hip in Nottingham

\begin{tabular}{lllll}
\hline & \multicolumn{2}{l}{ Age (yrs) } & & \\
\cline { 2 - 5 } & $\mathbf{5 5}$ to $\mathbf{6 4}$ & $\mathbf{6 5}$ to $\mathbf{7 4}$ & $\mathbf{7 5}$ to $\mathbf{8 4}$ & $\mathbf{8 5 +}$ \\
\hline Women & & & & \\
$\quad$ Number per year & 15 & 63 & 192 & 192 \\
$\quad$ Population & 29729 & 25780 & 19301 & 5107 \\
Incidence (\%) & 0.05 & 0.24 & 0.99 & 3.76 \\
Rate per 100 000 & 50 & 244 & 995 & 3760 \\
& & & & \\
Men & 12 & & & 39 \\
Number per year & 28903 & 22892 & 13329 & 2161 \\
Population & 0.04 & 0.14 & 0.28 & 1.80 \\
Incidence (\%) & 42 & 140 & 278 & 1805 \\
Rate per 100 000 & & & & \\
\hline
\end{tabular}

Table III. Calculated age and rates of gender-specific incidence per 100000 and the relative risk of a second fracture

\begin{tabular}{|c|c|c|c|c|}
\hline & \multicolumn{4}{|l|}{ Age (yrs) } \\
\hline & 55 to 64 & 65 to 74 & 75 to 84 & $85+$ \\
\hline \multicolumn{5}{|l|}{ Women } \\
\hline First fracture rate per 100000 & 50 & 244 & 995 & 3760 \\
\hline Second fracture rate per 100000 & 2290 & 2427 & 3389 & 2451 \\
\hline Calculated risk ratio $\left(95 \% \mathrm{Cl}^{*}\right)$ & 45.3 (13 to 154.7$)$ & 9.9 (5.1 to 19.2$)$ & $3.4(2.5$ to 4.7$)$ & $0.7(0.5$ to 0.9$)$ \\
\hline \multicolumn{5}{|l|}{ Men } \\
\hline First fracture rate per 100000 & 42 & 140 & 278 & 1805 \\
\hline Second fracture rate per 100000 & 1099 & 1081 & 2466 & 1813 \\
\hline Calculated risk ratio $(95 \% \mathrm{Cl})$ & 26.5 (3.5 to 201.5 ) & $7.8(1.9$ to 32.0$)$ & 8.9 (4.6 to 17.3$)$ & $1.0(0.4$ to 2.4$)$ \\
\hline
\end{tabular}

* $95 \% \mathrm{Cl}, 95 \%$ confidence interval

of a further fracture when compared with the risk of a first fracture of the hip in the population of the same age. By contrast, female patients aged $55<64$ years with a fracture had a 45 times increased risk of sustaining another fracture. A similar trend was observed in men.

\section{Discussion}

Previous studies examining second fractures of the hip have mainly been retrospective ${ }^{8-10,12,13}$ and such reports are dependent on adequate hospital records, take no account of the variable length of follow-up and fail to account for mortality after the first fracture. Therefore the true incidence of a second fracture cannot be accurately calculated. In our study, complete data on mortality was available, which showed precise determination of the incidence of a second fracture. Furthermore, the age-specific incidence of a second fracture was determined and compared with that of a primary fracture of the hip within the general population.

There have been prospective studies investigating the rates of a second fracture. Chapurlat et $\mathrm{al}^{14}$ studied a group of 632 women and calculated the risk of a second fracture to be $2.3 \%$ per year. Chiu et $\mathrm{al}^{15}$ followed 1514 patients admitted over five years and found that $2.3 \%$ suffered a fracture of the contralateral hip. Another prospective study of 501 primary hip fractures found the incidence of a second fracture to be $5 \%$ at one year and just over $8 \%$ at two years. ${ }^{22}$

Nymark et $\mathrm{al}^{23}$ set out to determine the interval between first and the second fracture in a study of 9990 fractures over ten years. An incidence of a second fracture of $8.7 \%$ was found. The risk of sustaining a second fracture was highest during the first 12 months after the first fracture, decreasing to a level equal to or below the incidence of the first fracture after this period of 12 months. Accordingly, the authors suggested that preventive strategies at the time of the first fracture should be implemented immediately. We also found that nearly half of the second fractures occurred within 12 months of the initial fracture.

In the population of Nottingham, the risk of sustaining a fracture of the hip increases between the ages of 55 and 85 years. Female patients who suffer a fracture between the ages of 55 and 64 years have 45 times the relative risk of sustaining a further fracture when compared with the normal population of this age. This is clearly an important subgroup of the population and all such patients should be referred for investigation and/or treatment for osteoporosis and the prevention of falls. By contrast, female patients over 84 years have a similar risk of a second fracture to that of the normal population. These findings are 
broadly parallel for men, although they have a lower relative risk of a second fracture between the age of 55 and 64 years. This significant difference in the age-specific incidence of a second fracture has not been observed before and has important implications for public-health measures. Current programmes for prevention of fractures are based on secondary care ${ }^{24,25}$ and the use of the guidelines of the National Institute for Clinical Excellence, ${ }^{26}$ which depend on the identification of fragility fractures as an indicator of potential osteoporosis and a risk factor for further fracture. However, in the very elderly, such programmes may need to be incorporated into primary care and address the entire population since the risk of a fracture appears to be similar, whether or not they have sustained a previous fracture. In our unit, the mean age for a primary fracture of the hip is now 81 years (17 to 105 ) and $60 \%$ of such patients are aged over 80 years. In the United Kingdom in 2003 there were more than one million people aged 85 years or older, representing $5.5 \%$ of the population aged over 50 years, and this number is steadily rising. ${ }^{27}$ Thus, the incorporation of programmes for prevention of fracture of the hip into primary care would be a major challenge for public-health.

We believe that this is the first prospective, observational study of a second hip fracture with accurate mortality data on all patients. Nevertheless, the limitations of our study must be recognised. Although we have a fairly stable study population, not all patients sustaining a second hip fracture will have been re-admitted to our institution; a small number might have moved away after the first fracture. This potential loss to follow-up meant that our estimate for the incidence of a second hip fracture was a best-case scenario and the lower $95 \%$ CI represented the lowest likely incidence in our population. However, it is highly improbable that this limitation in the design of our study could explain the 45 -fold increase in the relative risk of a second fracture of the hip occurring in women aged between 55 and 64 years compared with those aged 85 years and over.

The risk of a second fracture of the hip is $0.9 \%$ per year and patients appear to be at increased risk for the first 12 months after the initial fracture. The major difference in the age-specific incidence of a second fracture has not been observed before and has important implications for publichealth measures and programmes for prevention of fracture.

\section{Supplementary material}

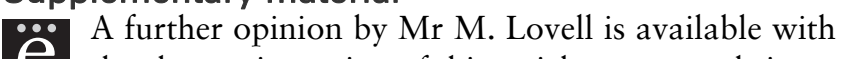
the electronic version of this article on our website at www.jbjs.org.uk
The authors wish to thank Dr. S. Armstrong for her help with the statistical analysis.

No benefits in any form have been received or will be received from a commercial party related directly or indirectly to the subject of this article.

\section{References}

1. Robinson CM, Royds M, Abraham A, et al. Refractures in patients at least forty-five years old: a prospective analysis of twenty-two thousand and sixty patients. J Bone Joint Surg [Am]2002;84-A:1528-33.

2. Johansson C, Mellstrom D. An earlier fracture as a risk factor for new fracture and its association with smoking and menopausal age in women. Maturitas 1996;24:97-106.

3. Klotzbuecher CM, Ross PD, Landsman PB, Abbott TA 3rd, Berger M. Patients with prior fractures have an increased risk of future fractures: a summary of the literature and statistical synthesis. J Bone Miner Res 2000;15:721-39.

4. Cummings SR, Black DM, Rubin SM. Lifetime risks of hip, Colles', or vertebral fracture and coronary heart disease among white postmenopausal women. Arch Intern Med 1989;149:2445-8

5. Anderson GH, Raymakers R, Gregg PJ. The incidence of proximal femoral fractures in an English county. J Bone Joint Surg [Br] 1993;75-B:441-4.

6. Johnell O, Gullberg B, Allander E, Kanis JA. The apparent incidence of hip fracture in Europe: a study of national register sources: MEDOS Study Group. Osteoporos Int 1992;2:298-302.

7. Lau EM, Cooper C, Fung H, Lam D, Tsang KK. Hip fracture in Hong Kong over the last decade: a comparison with the UK. J Public Health Med 1999;21:249-50.

8. Boston DA. Bilateral fractures of the femoral neck. Injury 1982;14:207-10.

9. Finsen V, Benum P. The second hip fracture: an epidemiologic study. Acta Orthop Scand 1986;57:431-3.

10. Schroder HM, Petersen KK, Erlandsen M. Occurrence and incidence of the second hip fracture. Clin Orthop 1993;289:166-9

11. Dretakis KE, Dretakis EK, Papakitsou EF, Psarakis S, Steriopoulos K. Possible predisposing factors for the second hip fracture. Calcif Tissue Int 1998;62:366-9.

12. Melton LJ 3rd, Ilstrup DM, Beckenbaugh RD, Riggs BL. Hip fracture recurrence: a population-based study. Clin Orthop 1982;167:131-8.

13. Dinah AF. Sequential hip fractures in elderly patients. Injury 2002;33:393-4.

14. Chapurlat RD, Bauer DC, Nevitt M, Stone K, Cummings SR. Incidence and risk factors for a second hip fracture in elderly women: the study of osteoporotic fractures. Osteoporos Int 2003;14:130-6.

15. Chiu KY, Pun WK, Luk KD, Chow SP. Sequential fractures of both hips in elderly patients: a prospective study. J Trauma 1992;32:584-7.

16. Wolinsky FD, Fitzgerald JF. Subsequent hip fracture among older adults. Am J Public Health 1994;84:1316-18

17. Yamanashi A, Yamazaki K, Kanamori M, et al. Assessment of risk factors for second hip fractures in Japanese elderly. Osteoporos Int 2005;16:1239-46.

18. Egan M, Jaglal S, Byrne K, Wells J, Stolee P. Factors associated with a second hip fracture: a systematic review. Clin Rehabil 2008;22:272-82.

19. No authors listed. Office for National Statistics. www.statistics.gov.uk (date last accessed 10 July 2009).

20. Kaplan EL, Meier P. Non-parametric estimation from incomplete observations. J Am Stat Assoc 1958; $53: 457-81$

21. No authors listed. Office for National Statistics. http://www.statistics.gov.uk/ census2001/pyramids/pages/00FY.asp (date last accessed 4 January 2010).

22. Lonnroos E, Kautiainen H, Karppi P, et al. Incidence of second hip fractures: a population-based study. Osteoporos Int 2007;18:1279-85.

23. Nymark T, Lauritsen JM, Ovesen 0, Röck ND, Jeune B. Short time-frame from first to second hip fracture in the Funen County Hip Fracture Study. Osteoporos Int 2006;17:1353-7.

24. McLellan AR, Gallacher SJ, Fraser M, McQuillian C. The fracture liaison service: success of a program for the evaluation and management of patients with osteoporotic fracture. Osteoporos Int 2003;14:1028-34.

25. Brankin E, Mitchell C, Munro R. Closing the osteoporosis management gap in primary care: a secondary prevention of fracture programme. Curr Med Res Opin 2005;21:475-82.

26. No authors listed. National Institute for Clinical Excellence. http://www.guidance.nice.org.uk/CG/Wave7/32 (date last accessed 10 July 2009).

27. No authors listed. Office for National Statistics. http://www.statistics.gov.uk/downloads/theme_compendia/foop05/OIderpeople2005.pdf (date last accessed 10 July 2009). 